\title{
ASSESSMENT OF DEBRIS FLOW DEPOSITION AREAS: EMPIRICAL METHODS, LABORATORY TESTS AND APPLICATION TO A CASE STUDY
}

\author{
C. ACHILLE ${ }^{1}$, D. DE WRACHIEN ${ }^{2}$, F. FASSI ${ }^{1} \&$ S. MAMBRETTI ${ }^{3}$ \\ ${ }^{1}$ BEST, Politecnico di Milano, Italy. \\ ${ }^{2}$ Department of Agricultural Engineering, State University of Milano, Italy. \\ ${ }^{3}$ School of Technology, UNICAMP, Brazil.
}

\begin{abstract}
Debris and hyper-concentrated flows are among the most destructive of all water-related disasters and in the recent years have attracted more and more attention from the scientific and professional communities and concern from public awareness, due to the increasing frequency with which they occur and the death toll they claim. The study of debris flows can be subdivided into three main topics: the assessment of the magnitude of the phenomenon, the study of debris flow motion and the determination of the extension of the deposits.

This last issue is of paramount importance from an engineering point of view, due to the fact that it determinates the areas that must be considered at risk, with all the consequences linked to the protection of population, and the predisposition of safety plans concerning different activities such as building construction. In this paper, a review of the most important empirical procedures of prediction of depositional areas is presented, with the aim to verify the applicability of the formulas to events different from those for which the methods were calibrated and then to try to unify them in order to originate a more reliable methodology.

Laboratory tests were carried out to integrate the data available in the literature. The experimental data have been recorded with photogrammetry methods and 3D models of the deposits have been designed and validated. Then, the carried out procedure is applied to a small catchment in the North of Italy. The proposed empirical method will allow one to improve both mitigation measures and hazard mapping procedures.
\end{abstract}

Keywords: Debris flow, deposits on alluvial fan, empirical method, laboratory tests.

\section{INTRODUCTION}

Debris flows are among the most destructive of all water-related disasters. Therefore, accurate prediction of their run-out distances, magnitudes and velocities plays a role of paramount importance for planning and designing appropriate structural and non-structural defence measures.

The study of debris flows can be subdivided into three main problems, which are usually studied separately by researchers: triggering, propagation and deposition [1].

In this paper, deposition phenomena have been studied in order to compute the extension of the deposits over the depositional area, the alluvial fans and the functions of different characteristics of the fan and the debris flow. The importance of the problem is related to the assessment of the area to be considered at risk, with all the consequences tied to the protection of population and the predisposition of safety plans or restrictions of possible activities or buildings $[2,3]$. Therefore, it is necessary to have methods that allow a reliable prediction of the debris flow hazardous areas; to this end, many empirical methods have been developed based on the data of real events and the on experimental tests carried out in laboratories, as will be shown in this paper.

At the first glance, empirical methods seem to be more inaccurate than physically based, but so far many uncertainties are still related with the estimation of the parameters describing 
the rheology of debris flow [4-6]: the estimation of debris flow depositional areas by physically based models is not less uncertain than that carried out by simpler empirical methods.

In this paper, a number of empirical methods are presented, and their applicability is tested to events different from those used for their calibration in terms of magnitude and material. The errors in the estimation of inundated areas and run-out lengths obtained through the empirical methods were calculated, comparing the actual areas and lengths with those predicted, in order to assess their reliability. Moreover, laboratory tests have been performed and a new formula has been developed.

\section{EMPIRICAL METHODS}

The empirical methods can be divided into two broad classes. The first category consists of the methods based on the regression of experimental data [7] or field data [8-12] and the latter category is related to the methods based on some physical (usually simplified) considerations about the motion of the debris flow, introducing the idea of gravitational and kinetic energy, which leads to the definition of the so-called 'energy line' [13-15].

Obviously, a parameter to be input in all these models is the event magnitude $V$, which is the volume involved in the event, tied to the return period, and is one of the main parameters influencing the extension of deposits. This magnitude is uncertain and the methods to evaluate it may lead to very sparse results $[16,17]$; for consistency, in this paper the event magnitude is supposed to be known and the same value has been used for different methods.

To apply the methods, a computer code has been developed. The geometrical data are given as input to the software as a text file with $x-y-z$ coordinates, regularized in a square grid; this kind of files can be produced as output from any Digital Terrain Model (DTM). Then, to draw the inundated area on the map, even if the values of the area and length are calculated by one of the proposed methods, the shape of the inundated area has to be determined. We decided (Fig. 1) that the area starts from the apex of the alluvial fan and it is an isosceles trapezoidal, with the length of the shorter parallel side equal to the width of the outlet cross section $b$, and the height equal to the computed run-out length $L$. Then, knowing the computed value of the inundated area, the value of the longer parallel side $B$ can be determined. In any case, in real cases the so-defined area is practically triangular.

The reviews of the analysed empirical methods are summarized in Table 1 . The main problem with empirical methods is that each of them was calibrated and tested with reference to

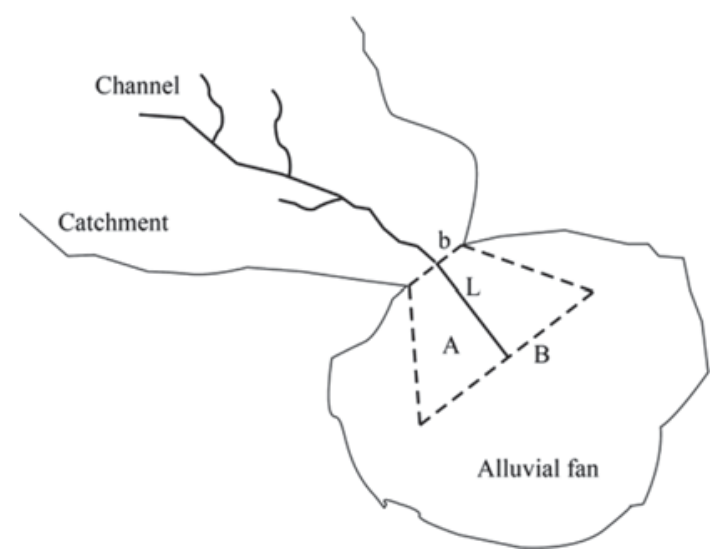

Figure 1: Schematization of the alluvial fan. 


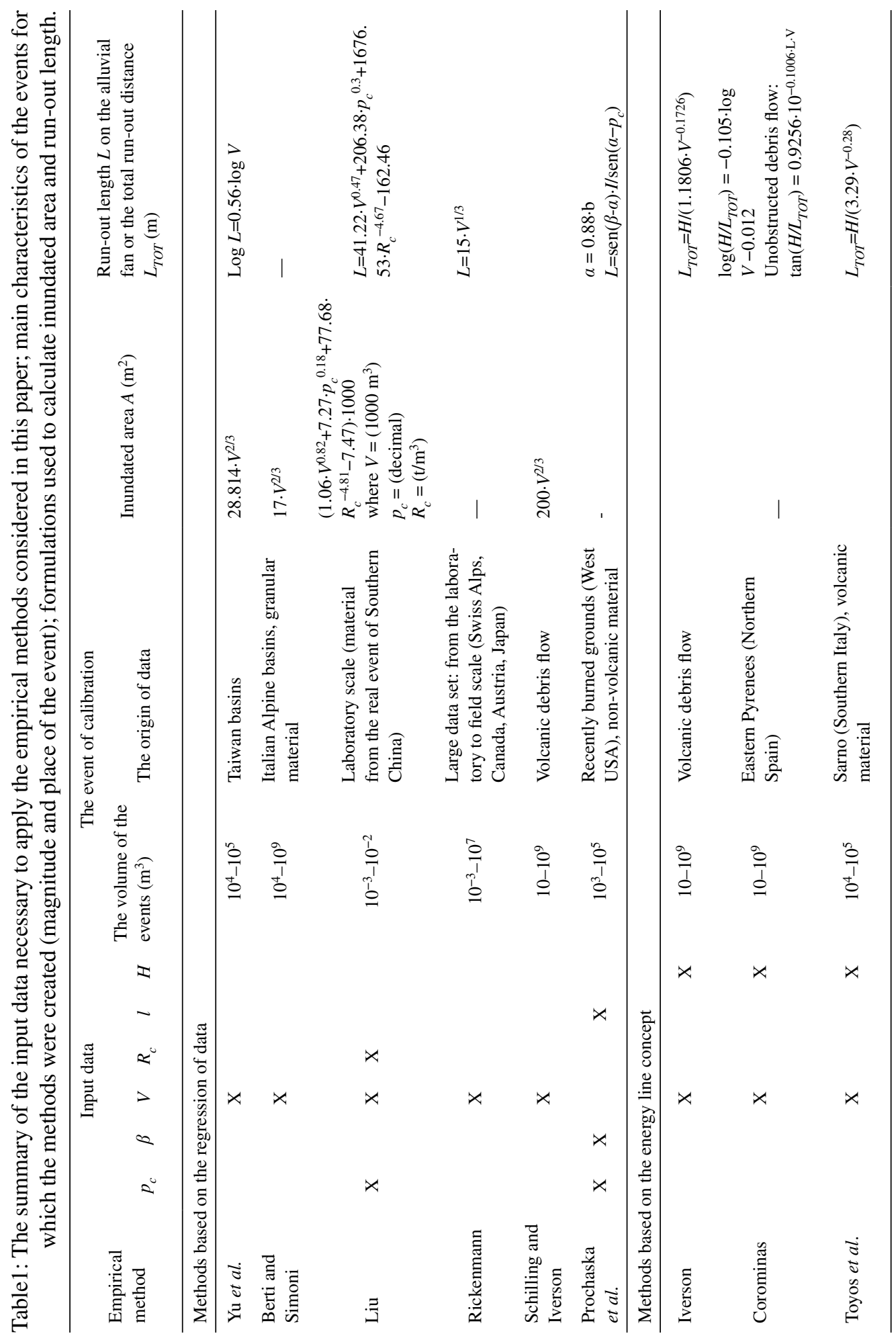


specific ranges of volumes and a specific kind of material. For example, granular debris flows have a behaviour very different from volcanic debris flows; some methods were obtained on the basis of a large range of volumes, such as the methods of Iverson and Corominas, whereas others were calibrated for a very specific sample of events, such as Sarno [15] or Taiwan events [8]; therefore, they give reasonable results only for catchments very similar to those for which they were purposely calibrated.

The aim of the research presented in this paper is the evaluation of the applicability of these empirical methods to other kinds of debris flow, at laboratory or field scale, having features in terms of magnitude and material different from those of the debris flows for which the methods were developed and calibrated. The errors in the estimation of inundated areas and run-out lengths obtained through the empirical methods were calculated, comparing the actual areas and lengths with those predicted, in order to assess their reliability.

\subsection{Methods based on regressions}

As previously mentioned, the methods based on the statistical regressions are based on a set of data, which is tried to be interpreted tying the unknowns inundated area $A$, and the run-out length of debris flow deposits on the alluvial fan $L$, with other known parameters, usually the magnitude $V$ of the event and sometimes with other catchment characteristics, e.g. the longitudinal profile of both the catchment and the fan [12].

The only method at laboratory scale checked in this paper is that of Liu [7], which takes into account parameters influencing debris flow motion, such as the fan slope $p_{c}$ and the debris flow bulk specific weight $R_{c}$. In this case, the material used in the experiments derived from debris flow events happened in Southern China.

Some methods $[10,12]$ calculate only the run-out length of debris flow; other methods allow one to calculate only the inundated area [9, 11]; whereas the methods of Liu [7] and Yu et al. [8] allow one to calculate both the run-out length and the inundated area. In any case, all the methods show a non-linear dependence between the inundated area and the debris flow volume, in particular all the methods, but Liu's, consider a dependence of area from the magnitude by power $2 / 3$. In any case, the dispersion of experimental data is always quite high, with correlation coefficients that vary between 0.65 and 0.87 .

\subsection{Energy line-based methods}

The concept of 'energy line' was originally developed for rock avalanches by Heim (1882) and then extended to debris flows by Iverson [18], who proposed a method based on the equality between the total potential energy $(\mathrm{MgH})$ and the total energy degraded to irrecoverable forms by the resisting forces $(M g R)$, thus lost during the motion through the distance $\left(L_{\mathrm{TOT}}\right)$. After that distance, debris flow stops because its energy is finished:

$$
M \cdot g \cdot H=M \cdot g \cdot R \cdot L_{T O T}
$$

where $M$ is the mass of the material involved in the debris flow, $g$ is the acceleration of gravity, $H$ is the vertical drop of the gravity driven mass and $L_{T O T}$ is the total run-out distance between the origin of the debris flow and the farthest point of the deposits on the alluvial fan. $R$ is the mobility ratio, which is a dimensionless friction coefficient that incorporates the effects of internal and external forces acting on the bed of the channel. 
Dividing each side of eqn (1) by $M g H L_{T O T}$, it yields

$$
R=H / L_{\text {TOT }}
$$

The value of the mobility ratio $R$ lies within the range of $0.25-0.50$ for small flows and decreases proportionally to the debris flow volume if it is $>10^{5} \mathrm{~m}^{3}$ [18]; it can be computed using the following equation:

$$
\delta\left(x-x^{\prime}\right)= \begin{cases}1 & \text { for } x=x^{\prime} \\ 0 & \text { elsewhere }\end{cases}
$$

in which $V$ is in cubic meters, and the distances are in meters.

Later, a number of authors developed their own model based on the same energetic concept, but calibrated on different events. Toyos et al. [15] developed an empirical model based on the volcanic debris flow events that occurred in May 1998 in the area of Sarno, Southern Italy. Again the model provides an approximation of the maximum distance $L_{\mathrm{TOT}}$ reached by the debris flow only as a function of the volume $V$ involved and the vertical drop $H$ of the gravity-driven mass:

$$
R=\frac{H}{L_{T O T}}=3.29 \cdot V^{-0.28}
$$

in which $V$ is in cubic meters, and the distances are in meters.

Corominas [14] analysed 254 landslide events mostly triggered by heavy rains in November 1982 in the Eastern Pyrenees, Northern Spain. The selected events include a great variety of materials, mechanisms of motion, topographic constraints and volumes involved. For every kind of movement he analysed the effect of obstacles and topographic constraints, demonstrating that the reach angle (the tangent of the reach angle is the mobility ratio) depends on the volume of landslides, the kind of movement, the obstacles and the topographic constraints on the path.

For debris flow events he obtained the following regressions, taking all the events recorded in the Eastern Pyrenees into account:

$$
\log \left(\frac{H}{L_{\text {TOT }}}\right)=-0.105 \cdot \log V-0.012
$$

While considering only unobstructed events, we obtain

$$
\tan \left(\frac{H}{L_{\text {TOT }}}\right)=0.9256 \cdot 10^{-0.1006 \cdot L \cdot V}
$$

in which $V$ is in cubic meters, and the distances are in meters.

In addition, for this category of methods the dispersion of experimental data is quite high, with the correlation coefficients varying within the range of $0.4-0.9$.

\section{LABORATORY TESTS}

The tests have been carried out in the Hydraulic Laboratory of the Politecnicodi Milano in order to evaluate the influence of different physical parameters on the extension of fan deposits. A saturated granular material with average diameter $D_{50}=0.005 \mathrm{~m}\left(D_{60} / D_{10}=2.15\right)$, density $\rho_{s}=2660 \mathrm{~kg} / \mathrm{m}^{3}$ and porosity 0.4 has been used. The experiments have been performed in a channel with a smooth plastic bottom, using three different bulk volumes $V$ $\left(0.002,0.004\right.$ and $\left.0.006 \mathrm{~m}^{3}\right)$. Therefore, considering the density of the solid material and its 


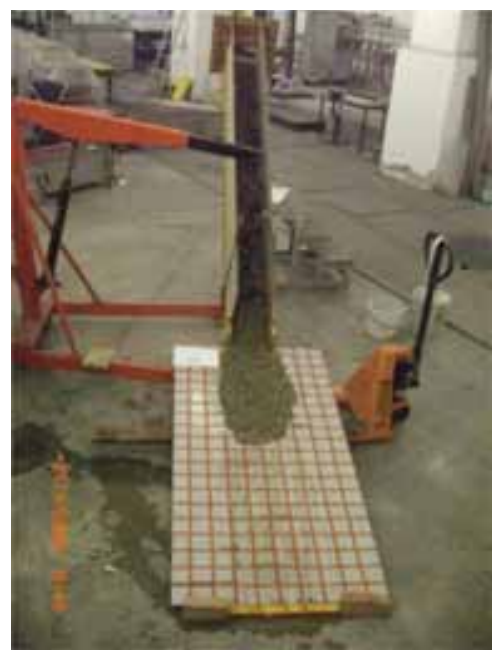

Figure 2: Experimental set-up.

porosity, the weight of the gravel used in each test was equal to $3.19,6.38$ and $9.58 \mathrm{~kg}$, respectively.

The experimental set-up is shown in Fig. 2. The channel has an adjustable slope $\left(20^{\circ}, 25^{\circ}\right.$, $30^{\circ}$ ), a length equal to $3.10 \mathrm{~m}$ and a rectangular cross section of $0.5 \mathrm{~m} \times 0.26 \mathrm{~m}$ ); a removable gate was placed in two different positions, at heights of 1 and $2 \mathrm{~m}$ over the fan; the gate represented the origin of the debris flow. At the end of the channel, a metal plane was positioned, representing the alluvial fan; the plane had an adjustable slope $\left(5^{\circ}-10^{\circ}-15^{\circ}\right)$ and was divided into a grid of squares $10 \mathrm{~cm} \times 10 \mathrm{~cm}$; experiments were carried out first on a smooth plane (Manning roughness $n=0.013 \mathrm{~s} \mathrm{~m}^{-1 / 3}$ ). Then a rough fan was constructed by gluing a plastic material (obtaining approximately $n=0.022 \mathrm{~s} \mathrm{~m}^{-1 / 3}$ ) or by using the same gravel used for the flow (obtaining approximately $n=0.029 \mathrm{~s} \mathrm{~m}^{-1 / 3}$ ).

A total number of 30 experiments were performed with different combinations of the parameters: the debris flow magnitude, the height of falling, the channel slope, the fan slope and the fan roughness. For each test, the following quantities were measured: the maximum deposit length and width, the thickness at the apex, centre and toe of the deposit, the deposit area and the deposit volume (which is the volume actually reaching the fan, while a part of the volume, generally small, remains on the bottom of the channel).

These test characteristics are summarized in Table 2.

\section{DATA ELABORATION}

In order to carry out the required parameters quickly and accurately, two photogrammetric approaches were followed. The former is the rigorous classical method called 'image rectification', which allows accurate 2D measurements in the XY plane and consequently, in this case, was used to compute the length and the width of the deposit during the flow. To perform this, it is necessary to tape the simulated flow using an HD-calibrated camera and then to extract some image frames of the video at the time spots of interest; later, the photogrammetric transformation is applied on the single extracted frames. To obtain $2 \mathrm{D}$ accurate measurements from the images, two steps were followed: (i) the elimination of the distortions caused by the camera lenses applying back to the image the camera inner calibration 
Table 2: The experimental test characteristics and results.

\begin{tabular}{|c|c|c|c|c|c|c|c|}
\hline & Roughness & $\begin{array}{l}\text { The slope } \\
\text { of the } \\
\text { channel }\left(^{\circ}\right)\end{array}$ & $\begin{array}{l}\text { The slope } \\
\text { of the } \\
\text { fan }\left(^{\circ}\right)\end{array}$ & $\begin{array}{l}\text { Volume, } \\
V[1]\end{array}$ & $\begin{array}{c}\text { Dropheight, } \\
H(\mathrm{~m})\end{array}$ & $\begin{array}{c}\text { Inundated } \\
\text { area, } \\
A\left(\mathrm{~m}^{2}\right)\end{array}$ & $\begin{array}{c}\text { The run-out length } \\
\qquad L(\mathrm{~m})\end{array}$ \\
\hline 1 & \multirow{11}{*}{ Smooth } & 30 & \multirow{5}{*}{5} & 2 & \multirow{3}{*}{2} & 0.145 & 0.62 \\
\hline 2 & & & & 4 & & 0.363 & 1.04 \\
\hline 3 & & & & 6 & & 0.530 & 1.19 \\
\hline 4 & & & & 4 & \multirow[t]{2}{*}{1} & 0.160 & 0.58 \\
\hline 5 & & & & 2 & & 0.295 & 0.85 \\
\hline 6 & & & \multirow{3}{*}{10} & 4 & \multirow[t]{2}{*}{2} & 0.470 & 1.03 \\
\hline 7 & & & & 6 & & 0.255 & 0.95 \\
\hline 8 & & & & 4 & \multirow[t]{2}{*}{1} & 0.470 & 1.39 \\
\hline 9 & & & \multirow{5}{*}{15} & 2 & & 0.810 & 2.00 \\
\hline 10 & & & & 4 & \multirow[t]{2}{*}{2} & 0.094 & 0.41 \\
\hline 11 & & & & 6 & & 0.218 & 0.62 \\
\hline 12 & & & & 4 & \multirow[t]{2}{*}{1} & 0.302 & 0.82 \\
\hline 13 & & & & 2 & & 0.063 & 0.28 \\
\hline 14 & & & \multirow{4}{*}{5} & 4 & \multirow[t]{2}{*}{2} & 0.142 & 0.45 \\
\hline 15 & & & & 6 & & 0.217 & 0.57 \\
\hline 16 & & & & 4 & \multirow[t]{2}{*}{1} & 0.065 & 0.28 \\
\hline 17 & & & & 2 & & 0.161 & 0.49 \\
\hline 18 & \multirow{7}{*}{$\begin{array}{l}\text { Rough } \\
\text { (plastic) }\end{array}$} & & \multirow{4}{*}{10} & 4 & \multirow[t]{2}{*}{2} & 0.196 & 0.54 \\
\hline 19 & & & & 6 & & 0.340 & 0.86 \\
\hline 20 & & & & 4 & \multirow[t]{2}{*}{1} & 0.440 & 1.13 \\
\hline 21 & & & & 2 & & 0.550 & 1.40 \\
\hline 22 & & & \multirow{3}{*}{$15^{\circ}$} & 4 & \multirow[t]{2}{*}{2} & 0.159 & 0.44 \\
\hline 23 & & & & 6 & & 0.190 & 0.54 \\
\hline 24 & & & & 4 & 1 & 0.251 & 0.70 \\
\hline 25 & \multirow{3}{*}{$\begin{array}{l}\text { Rough } \\
\text { (gravel) }\end{array}$} & & 5 & 2 & \multirow{3}{*}{2} & 0.069 & 0.26 \\
\hline 26 & & & 10 & 2 & & 0.081 & 0.33 \\
\hline 27 & & & 15 & 2 & & 0.106 & 0.40 \\
\hline 28 & \multirow{3}{*}{$\begin{array}{l}\text { Rough } \\
\text { (plastic) }\end{array}$} & 15 & \multirow{3}{*}{10} & 4 & \multirow{3}{*}{2} & 0.127 & 0.38 \\
\hline 29 & & 20 & & 4 & & 0.152 & 0.48 \\
\hline 30 & & 25 & & 4 & & 0.145 & 0.62 \\
\hline
\end{tabular}

parameters and (ii) the transformation of the perspective projection typical of the camera in orthographic projection using a method called image rectification. Both analytical and geometrical methods are tested (Fig. 3).

The camera used in the laboratory was a Canon 5D Mark II with a $35 \mathrm{~mm}$ fix lens precalibrated on site. The camera was placed over the plane at a height of $\sim 3.3 \mathrm{~m}$ to obtain an image resolution of $\sim 0.5 \mathrm{~mm}$ on the ground and that can provide a final pixel size on the rectified image of $\sim 2 \mathrm{~mm}$.

The parameters to be measured were the thicknesses at the apex, centre and toe of the deposit, the deposit area and its volume. These are typically 3D measurements that need a 3D reconstruction of the deposit. The 3D model is created using the latter mentioned photogrammetric method, the so-called 'image matching', which allows one to build 3D points models of the inquired object from a series of images of the same scene taken from different positions around it. The procedure has been completely computerized (Fig. 4). 


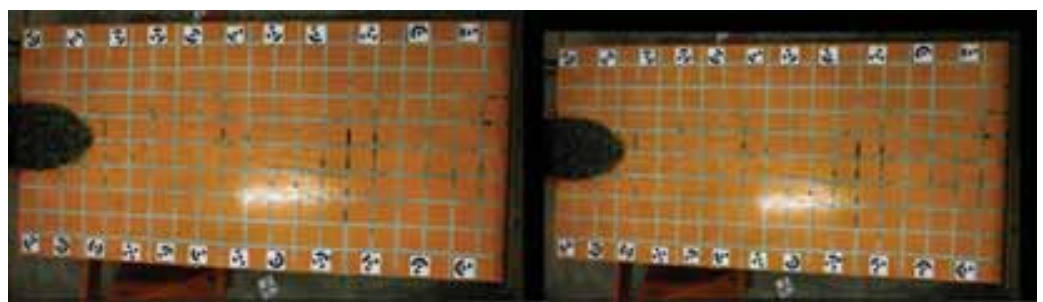

Figure 3: The original frame (left-hand side) and the same corrected from image distortion (right-hand side).

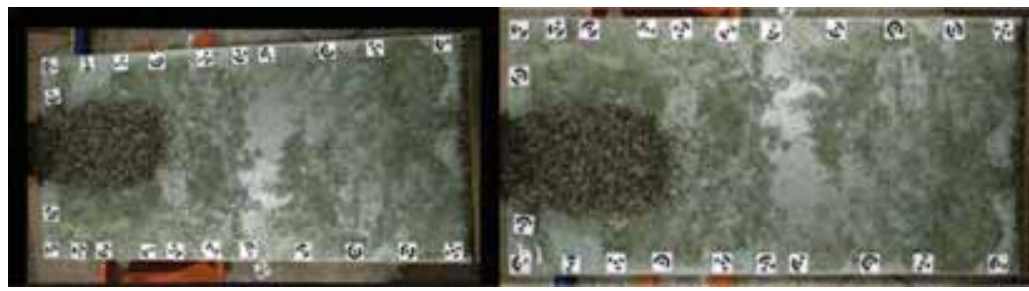

Figure 4: An undistorted video frame with a ground resolution of $0.6 \mathrm{~mm}$ (left-hand side) and the corresponding rectified images with a ground resolution of $1.8 \mathrm{~mm}$ (righthand side).

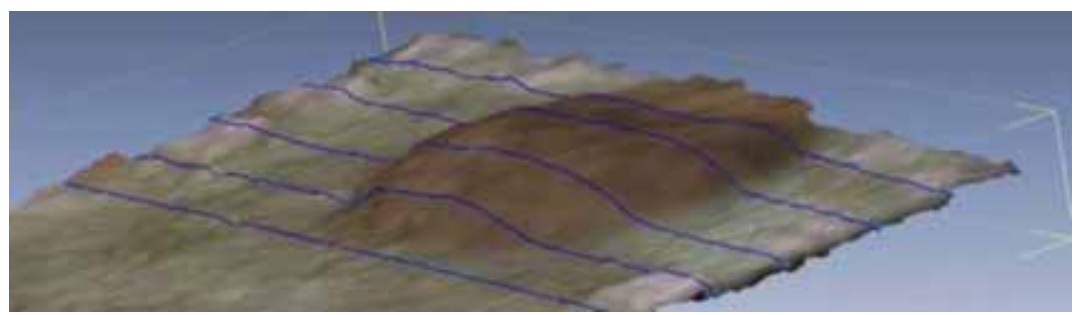

Figure 5: The 3D DSM with the automatic contour extraction of the deposit.

At least 15 images have to be collected, and to this end the so-called multi-image acquisition set around the object was used, which means a number of photos of the same object were taken, each of them with a different capture angle but with a very short distance between adjacent captures. Automatic procedures of image orientation were used to calculate automatically the camera's positions and external orientations; then image matching procedures were used to extract a raw 3D point cloud of the captured scene. The achieved point models had a resolution of $\sim 2 \mathrm{~cm}$. In fact, this is not a very high resolution, but this quite poor result is mainly due to the choice to speed up the elaboration using low-middle resolution images in the process. In fact, these types of elaborations are completely automatic but can be very time-consuming: the elaboration time grows exponentially with the resolution of the image.

Moreover, the presence of water on the surface brings errors in the automatic procedure of point matching with a consequent decrease in resolution. The presence of a false corresponding point among images should be eliminated in the final 3D model with a consequent loss of detail. Some post-processes are then necessary to clean the point cloud and create the final DSM to be used to extract, automatically or manually, the required 3D information as 3D coordinates, contour areas and volumes (Fig. 5). 
Table 3: The range of validity of empirical methods and scale factor $\lambda$ applied to the laboratory data.

\begin{tabular}{lcr}
\hline Method & Range $\left(\mathrm{m}^{3}\right)$ & \multicolumn{1}{c}{$\lambda$} \\
\hline Yu et al. & $10^{4}-10^{5}$ & 250 \\
Berti and Simoni & $10^{4}-10^{9}$ & 1000 \\
Liu & $10^{-3}-10^{-2}$ & 1 \\
Rickenmann & $10^{3}-10^{7}$ & 100 \\
Schilling and Iverson & $10^{4}-10^{9}$ & 1000 \\
Prochaska et al. & $10^{3}-10^{4}$ & 100 \\
Iverson & $10^{4}-10^{9}$ & 1000 \\
Corominas & $10^{4}-10^{9}$ & 250 \\
Toyos et al. & $10^{4}-10^{5}$ & 250 \\
\hline
\end{tabular}

\section{THE EVALUATION OF THE APPLICABILITY OF EMPIRICAL METHODS TO EXPERIMENTAL DATA}

In order to evaluate the applicability of empirical methods to the laboratory results, the experimental data have been scaled to fall into the range of applicability of the different methods, i.e. in the range of debris flow volumes for which the formulation had been calibrated. This range with the related scale factor is reported in Table 3. As only geometric values (lengths, areas and volumes) are involved in the calculations, a simple geometrical scaling was applied, multiplying the volume of the laboratory test by $\lambda^{3}$. As can be seen, since Liu's data were carried out in laboratory, no scale factor was needed.

Moreover, it has to be underlined that, when the scale coefficient had to be set equal to 1000 , the actual meaning of the carried out results is very low, because if we apply the geometrical scale factor to the single solid grains, the average dimension of the solid material would be approximately equal to $5 \mathrm{~m}$, which is neither realistic nor common.

As a measure of the error carried out when the existing methods are applied to the experimental data collected in the laboratory, the ratio $F$ s between the area $A_{\text {calculated }}$ (or the length $L_{\text {calculated }}$ ) obtained by the empirical method and the measured area $A_{\text {actual }}$ (or length $L_{\text {actual }}$ ) was calculated for every laboratory test carried out in the laboratory:

$$
\begin{aligned}
& F S_{A}=\frac{A_{\text {calculated }}}{A_{\text {actual }}}, \\
& F S_{L}=\frac{L_{\text {calculated }} .}{L_{\text {actual }}} .
\end{aligned}
$$

The minimum, maximum and average values obtained for each method are summarized in Table 4 . When the ratio is $<1$, the method underestimates the actual deposit extension; otherwise, the method overestimates the debris flow extension. Hence, the ratio can be considered as a 'safety factor', in the sense that it represents a factor for which it is necessary to divide the area/length calculated by the formula in the way to obtain the real extension of debris flow deposit.

As can be seen, the obtained $F s$ values are very scattered and some of the carried out results are far from acceptable. 
Table 4: The values of the ratio $F s$ for area and length obtained from laboratory tests.

\begin{tabular}{|c|c|c|c|c|c|c|}
\hline \multirow{2}{*}{ Methods } & \multicolumn{3}{|c|}{$F s_{A}$} & \multicolumn{3}{|c|}{$F s_{L}$} \\
\hline & Minimum & Average & Maximum & Minimum & Average & Maximum \\
\hline \multicolumn{7}{|c|}{ Based on the regression of data } \\
\hline Yu et al. & 1.05 & 2.86 & 4.73 & 1.08 & 2.55 & 4.02 \\
\hline $\begin{array}{l}\text { Berti and } \\
\text { Simoni }\end{array}$ & 0.62 & 1.69 & 2.79 & - & - & - \\
\hline Liu & 1.30 & 4.81 & 11.30 & 1.27 & 3.70 & 6.84 \\
\hline Rickenmann & - & - & - & 1.29 & 3.52 & 5.98 \\
\hline $\begin{array}{l}\text { Schilling and } \\
\text { Iverson }\end{array}$ & 7.32 & 19.85 & 32.82 & - & - & - \\
\hline Prochaska et al. & - & - & - & 0.25 & 0.84 & 1.67 \\
\hline $\begin{array}{l}\text { New regression } \\
\text { line proposed } \\
\text { by the authors } \\
\text { in this paper }\end{array}$ & 0.46 & 1.21 & 1.93 & 0.47 & 1.19 & 1.88 \\
\hline \multicolumn{7}{|c|}{ Energy-line-based } \\
\hline Iverson & & & & 4.01 & 5.93 & 7.48 \\
\hline Corominas & & & & 1.19 & 1.85 & 2.81 \\
\hline Toyos et al. & & & & 2.56 & 3.99 & 6.32 \\
\hline
\end{tabular}

On the one hand, Schilling and Iverson's method leads to an estimation of the deposit area up to 30 times higher of the actual one. This is due to the fact that this method is not really applicable to laboratory data, since it was developed for volcanic debris flow (lahars) with rheological characteristics very different from those of the granular material we used.

On the other hand, the method by Prochaska et al. [12] gives, on average, an underestimation of the run-out length, but this method was also calibrated for a very specific kind of debris flow, happening on recently burned grounds.

In general, the other methods give an overestimation of the inundated area and the run-out length; hence, if they were applied for the delimitation of an area potentially at the risk of debris flow, they would be on the safe side. The problem is that their predictions are too uncertain, since they could overestimate, on average, the debris flow extension by up to six times the real extension.

Through the interpolation of all available data collected from the literature - volumes, run-out lengths and/or depositional areas of real debris flow events as in [7-10, 12] — and from the laboratory tests performed in our laboratory, new global formulas for the evaluation of depositional areas and run-out lengths on the alluvial fan as functions of the debris flow magnitude have been developed, with the aim of achieving a formulation giving acceptable results for a very wide range of volumes and materials. The resulting formula fits the data of debris flow both at the laboratory scale and at the field scale, as shown in Figs 6 and 7. 


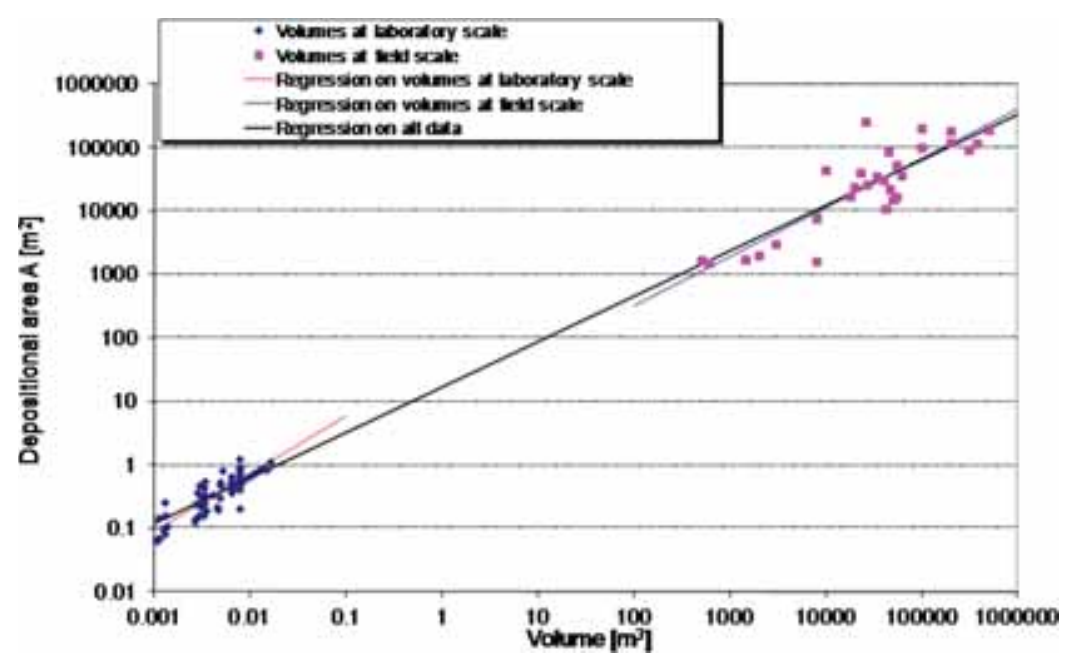

Figure 6: The Authors' formula for depositional area estimation.

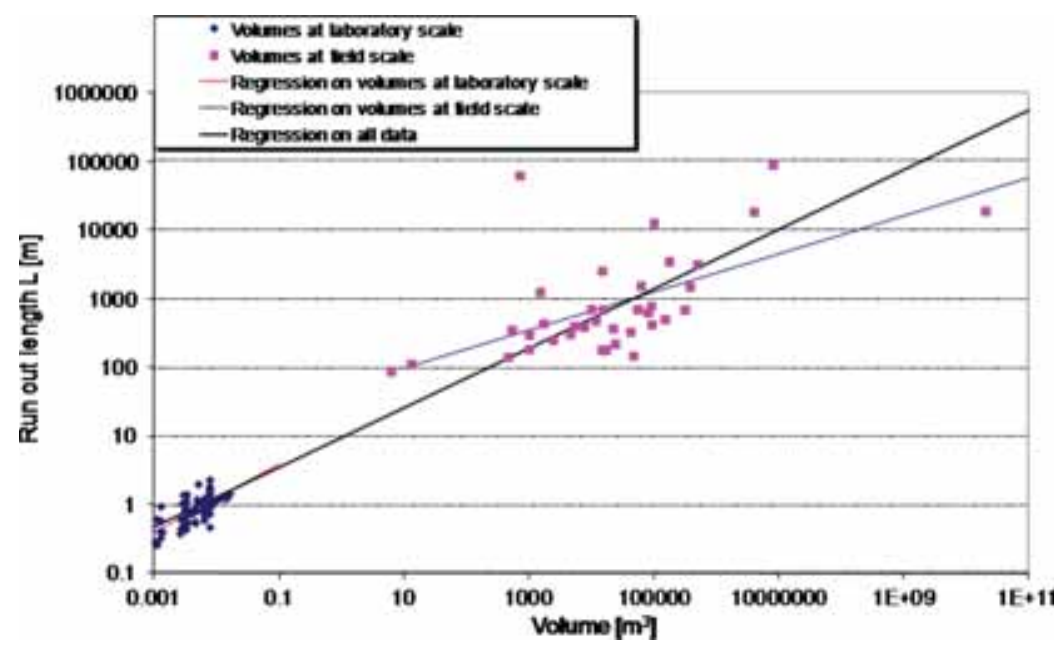

Figure 7: The new regression formula for run-out length estimation.

The formula for the new regression line for depositional area estimation (Fig. 5), based on all the available experimental data, is

$$
A=16.5 \cdot V^{0.72}
$$

and the related correlation coefficient is $R^{2}=0.98$.

The formula for the new regression line for depositional length estimation (Fig. 6), based on all the available experimental data, is

$$
L=9.34 \cdot V^{0.434}
$$

and the related correlation coefficient is $R^{2}=0.93$. 
Table 5: The average, maximum and minimum safety factors calculated on all the available events, applying the new formulas proposed.

\begin{tabular}{lll}
\hline & \multicolumn{2}{c}{ Granular debris flows } \\
& $F s_{A}$ & $F s_{L}$ \\
\hline Minimum & 0.28 & 0.18 \\
Average & 1.12 & 1.31 \\
Maximum & 3.13 & 6.70 \\
\hline
\end{tabular}

On average, the new formula when applied to all the available data gives an $F s_{A}$ equal to 1.16 for the depositional area and an $F s_{L}$ equal to 1.4 for the run-out length. The average, maximum and minimum safety factors obtained from the application of the new formula to the available data are summarized in Table 5.

Hence, on average, the results obtained by these formulas are good compared with the mean $F s$ obtained by the pre-existing methods presented in Table 4 and acceptable if used for designing purposes. However, it is to be underlined that the problem is still the high dispersion of data.

\section{APPLICATION TO A CASE STUDY}

The Val Gola catchment $\left(3.5 \mathrm{~km}^{2}\right)$ located in the eastern Italian Alps (Val Camonica, Lombardy Region) belongs to the Oglio river basin. The catchment shows an almost elliptical form, with the main axes oriented in the NW-SE direction (Fig. 8).

The main valley reaches $1700 \mathrm{~m}$ a.s.l. (Monte Alto) and closes at $195 \mathrm{~m}$ a.s.l. (Fermata Castello). The mean slope of the channel is $\sim 21.5^{\circ}$, and the length is $\sim 3.8 \mathrm{~km}$. The area is of great importance from both economic and touristic points of view (Iseo lake and Franciacorta vineyards).

Geologically, the catchment is characterized by different lithologies, essentially represented by evaporite and carbonate sedimentary units chronologically dated between low and medium Triassic, often covered by recent deposits of the Quaternary. Quaternary fans are mostly present in the lower part of the valley. According to their genesis, these deposits can be classified as gravitative fans or screes, deposits due to fluvial processes and glacial deposits (moraines). The upper Quaternary fans outcropping in different areas and having different stratigraphical positions are mainly present in the southern part of the catchment. In conclusion, the bulk density estimated for the material involved in the debris flow is $\sim 2000 \mathrm{~kg} / \mathrm{m}^{3}$.

The catchment ends in an alluvial fan with a gentle slope of $11^{\circ}$. On the top of the fan, there are heaps of debris of heterogeneous size that disperse the water downstream of the closing section. As in the catchment there is not a defined and perennial stream, probably the debris are transported downstream as a result of the formation of debris flows triggered by heavy rains, rather than solid transport [19].

The morphologic characteristics of the catchment and the fan are summarized in Table 6.

Field surveys identified an area on the alluvial fan of Val Gola having a length of 500-600 $\mathrm{m}$, non-colonized by vegetation, and therefore supposed to be the subject to the most frequent debris flow events. The estimation of the lengths for a higher return period is more difficult, especially if it is required to tie it with the magnitude. However, engineers would have at least $2000 \mathrm{~m}$ as a safety distance in order to be protected even from larger events. 


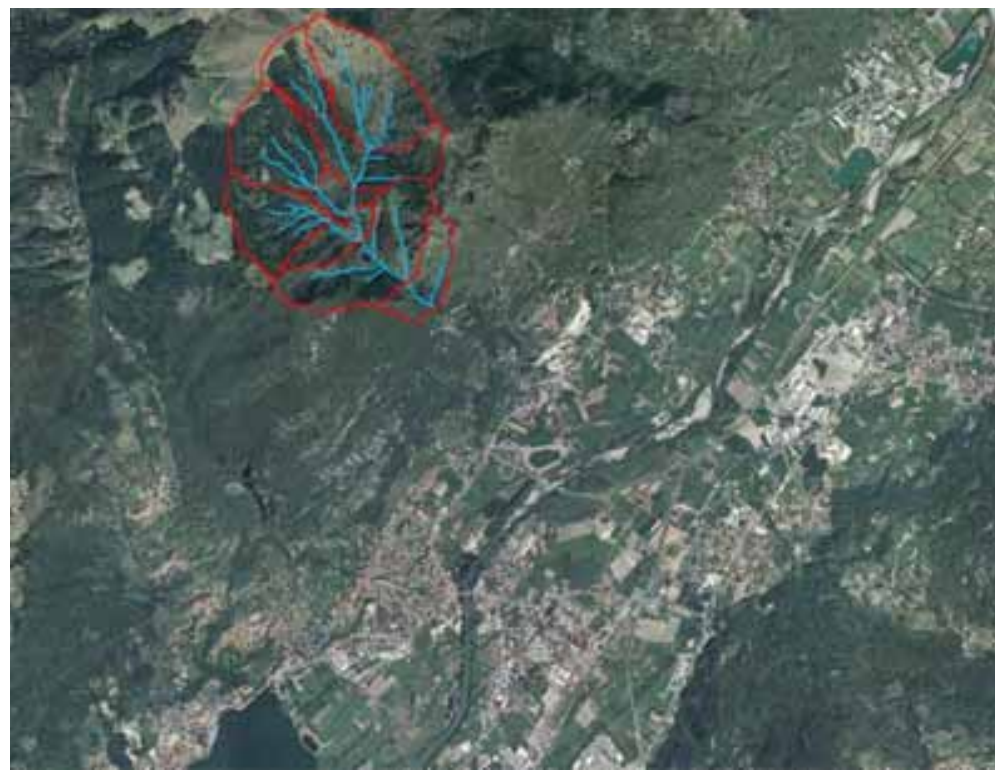

Figure 8: The map of Val Gola catchment.

Table 6: The Val Gola catchment characteristics.

\begin{tabular}{lc}
\hline The area of the catchment $\left(\mathrm{km}^{2}\right)$ & 3.5 \\
The maximum elevation (head of the thalweg) (m a.s.l.) & 1700 \\
The minimum elevation (fan apex) (m a.s.l.) & 195 \\
The length of the thalweg (km) & 3.8 \\
The slope of the thalweg $\left({ }^{\circ}\right)$ & 21.5 \\
The slope of the fan $\left(^{\circ}\right)$ & 11.3 \\
\hline
\end{tabular}

The solid discharge $Q_{s}$ mobilized in a debris flow has been evaluated through the Takahashi hydrological method [20], which states that the solid discharge is directly linked to the liquid discharge $Q_{L}$. As the liquid discharge generated from a meteorological event has a specific return period $T_{R}$, it was possible to calculate the solid discharge associated with each liquid discharge $Q_{L}\left(T_{\mathrm{R}}\right)$, and then by applying a convolution through an instantaneous unitary hydrograph the liquid and the corresponding solid volume were calculated [16, 17].

The results are summarized in Table 7 , where the minimum and maximum values of the expected debris flow are presented; the two values depend on the degree of saturation of the soil and the concentration of the material in the debris flow. Then, the average value of the expected debris flow volume has to be used for the successive calculations about deposits extension.

On the basis of the DTM of Val Gola fan, the inundated areas $A$ and depositional lengths $L$ computed by the different methods presented in this paper are summarized in Tables 8 and 9 .

It has to be noted that the method proposed by Prochaska et al. [12] does not the debris flow magnitude into account and therefore is unable to evaluate the different extensions of the deposits caused by the variation of the volumes involved. 
Table 7: The estimated debris flow magnitude for Val Gola catchment (after $[16,17,19])$.

\begin{tabular}{lccc}
\hline \multirow{2}{*}{ Return period (years) } & \multicolumn{3}{c}{ Magnitude $V\left(\mathrm{~m}^{3}\right)$} \\
& Minimum & Maximum & Mean \\
\hline 50 & 150000 & 230000 & 190000 \\
100 & 170000 & 270000 & 220000 \\
200 & 200000 & 300000 & 250000 \\
\hline
\end{tabular}

Table 8: The estimated depositional areas.

\begin{tabular}{lrrrr}
\hline Depositional area $A\left(10^{3} \mathrm{~m}^{2}\right)$ & \multicolumn{5}{c}{ Magnitude $\left(10^{3} \mathrm{~m}^{3}\right)$} \\
\hline & 20 & 190 & 220 & 250 \\
\hline Berti and Simoni & 21 & 56 & 61 & 67 \\
Yu et al. & 12 & 95 & 105 & 114 \\
Liu & 13 & 79 & 89 & 98 \\
Schilling and Iverson & 151 & 660 & 728 & 793 \\
New interpolating formula for depositional area & $\mathbf{2 0}$ & $\mathbf{9 9}$ & $\mathbf{1 1 0}$ & $\mathbf{1 2 1}$ \\
\hline
\end{tabular}

Table 9: The estimated run-out lengths.

\begin{tabular}{lrrrr}
\hline Run-out length $L(\mathrm{~m})$ & \multicolumn{5}{c}{ Magnitude $\left(10^{3} \mathrm{~m}^{3}\right)$} \\
\hline & 20 & 190 & 220 & 250 \\
\hline Yu et al. & 262 & 903 & 981 & 1054 \\
Liu & 201 & 514 & 549 & 581 \\
Rickenmann & 413 & 862 & 905 & 944 \\
Prochaska et al. & \multicolumn{4}{c}{645} \\
Corominas (for debris flow events) & 908 & 2075 & 2161 & 2236 \\
Iverson & 3561 & 6968 & 7239 & 7482 \\
Toyos et al. & 3845 & 10396 & 10983 & 11515 \\
New interpolating formula for run-out length & $\mathbf{7 0 0}$ & $\mathbf{1 8 2 4}$ & $\mathbf{1 9 4 3}$ & $\mathbf{2 0 5 2}$ \\
\hline
\end{tabular}

Furthermore, Liu's model is the only one based on laboratory tests, characterized by volumes $\left(0.0027-0.016 \mathrm{~m}^{3}\right)$ much smaller than natural events.

Analysing the results, the methods by Berti and Simoni [9], Yu et al. [8] and Liu [7] provide comparable estimations of inundation areas. In contrast, the method by Iverson and Schilling [11] provides an estimation of depositional area one order of magnitude larger than the others, due to the previously mentioned fact that it was calibrated on lahars.

About the run-out length, the results of the methods by Yu et al. [8], Liu [7], Rickenmann [10] and Prochaska et al. [12] are all of the same order of magnitude. 
In contrast, the method by Corominas [14] furnishes the results of the same order of magnitude of the those obtained by the new regression formulation, whereas the methods by Iverson [18] and Toyos et al. [15] give results much higher and unlikely. As previously mentioned, this could be due to the fact that these two methods have been calibrated on volcanic events, and therefore their application to the case of Val Gola is not appropriate.

Inundated areas and run-out lengths were also calculated for a debris flow magnitude of 20 $000 \mathrm{~m}^{3}$, which can be considered as the magnitude of a frequent event.

On the basis of this debris flow magnitude, the run-out lengths estimated by the Authors' formula and by Corominas method are of the same order of magnitude of the results of the field analysis, with a small overestimation of the run-out length, i.e. in any case on the safe side.

\section{CONCLUSIONS}

This study confirmed that as the inundated area and the run-out length of a debris flow strongly depend on the physical parameters characterizing both the debris flow mixture (water content, density of the material, etc.) and the environment in which the debris flow develops and deposits (e.g. the alluvial fan roughness), it is very difficult to predict with sufficient reliability the extension of debris flow deposits using empirical formulas because the results are very sparse; therefore these formulas obtained and calibrated on very specific data sets or experimental catchments can be used as instruments to estimate depositional areas and run-out lengths for a generic catchment, in the phase of planning or designing only by highly trained technicians or engineers with the help of field analysis.

However, from the application of the empirical methods both to laboratory data, it results that satisfactory results can be obtained with the Authors' formulas for both area and run-out length and with the method of Corominas for the run-out length only.

This latter method (or family of methods), which is based on physical considerations, although simplified, should be more deeply investigated.

However, developments of this research will be towards the assessment of a model more complex and physically based, able to take into account all the relevant parameters and to produce more reliable results to be used in real planning.

Moreover, photogrammetric measurement techniques have been tested. They proved to be very useful to take quick, cheap but accurate and automatic measurement during laboratory tests. Future developments of the methodology will be the installation of a fixed laboratory photogrammetric set with fixed capture positions and good illumination in order to increase the acquisition quality and the final measurement accuracy. The improvements in the accuracy and speed of the methodologies used to carry out automatic 3D modelling from images are very important in the hydro-geological and environmental field, where these measurements have to be repetitively performed both in the laboratory and in the field, to monitor dangerous mass of sediments.

The method has been applied to a small catchment in the North of Italy, showing that the method performs adequately, even if, in real cases, the empirical and mathematical methods should be always coupled with the field work.

\section{NOMENCLATURE}

$\alpha \quad$ angle of reach;

$b \quad$ width of the cross section of the channel (m);

A inundated area $\left(\mathrm{m}^{2}\right)$;

$A_{\text {actual }} \quad$ debris flow inundated area measured in laboratory test $\left(\mathrm{m}^{2}\right)$; 


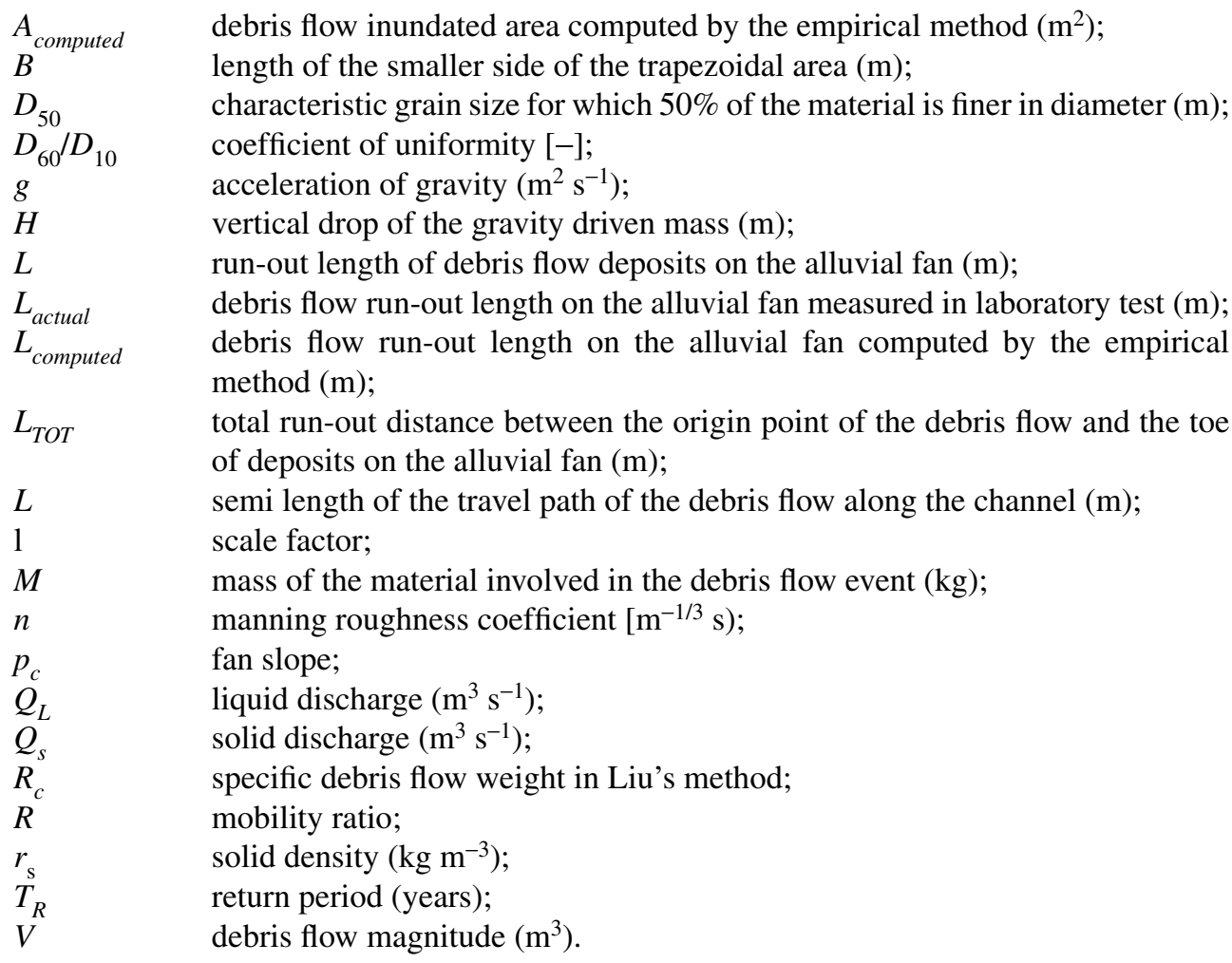

\section{REFERENCES}

[1] Lorenzini G., Brebbia C. \& Emmanouloudis D. (eds.), Monitoring, simulation, prevention and remediation of dense and debris flows, WIT Press: Southampton, UK, 2006. doi: http://dx.doi.org/10.2495/DEB06

[2] Einstein, H., Special lecture: "Landslide risk assessment procedure". Int. Symposium on Landslides. Landslide, Vol. 2, ed. C. Bonnard, pp. 1075-1090, 1988.

[3] Schultz, B., Flood management under rapid urbanization and industrialization in floodprone areas: a need for serious consideration. Irrigation and Drainage, 55(Suppl. 1), pp. 3-8, 2006. doi: http://dx.doi.org/10.1002/ird.237

[4] Iverson, R., The debris-flow rheology myth. Debris-flow hazards mitigation: Mechanics, prediction, and assessment, Vol 1, eds. D. Rickenmann \& C. Chen, Millpress: Rotterdam, pp. 303-314, 2003.

[5] Mambretti, S., Larcan, E. \& De Wrachien, D., Theoretical and experimental analysis of debris flow: Rheology and two-phase modelling. Irrigation and drainage, 57(5), pp. 555-570, 2008. doi: http://dx.doi.org/10.1002/ird.383

[6] Mambretti, S., Larcan, E. \& De Wrachien, D., 1D modelling of dam-break surges with floating debris. Biosystems Engineering, 100(2), pp. 297-308, 2008. doi: http://dx.doi. org/10.1016/j.biosystemseng.2008.02.011

[7] Liu, X., Size of debris flow deposition: Model experiment approach. Environmental Geology, 28(2), pp.70-77, 1996. doi: http://dx.doi.org/10.1007/s002540050079

[8] Yu, F., Chen, C., Chen, T. Hung, F. \& Lin, S., A GIS process for delimitating areas potentially endangered by debris flow. Natural Hazards, 37, pp.169-189, 2006. doi: http://dx.doi. org/10.1007/s11069-005-4666-8 
[9] Berti, M. \& Simoni, A., Prediction of debris flow inundation areas using empirical mobility relationships. Geomorphology, 90, pp. 144-161, 2007. doi: http://dx.doi.org/10.1016/ j.geomorph.2007.01.014

[10] Rickenmann, D., Empirical relationships for debris flows. Natural Hazards, 19, pp. 47-77, 1999. doi: http://dx.doi.org/10.1023/A:1008064220727

[11] Iverson, R. \& Schilling, S., Automated, reproducible delineation of zones at risk from inundation by large volcanic debris flows. Proceedings of first international conference on debris-flow hazards mitigation: Mechanics, prediction and assessment, ASCE: San Francisco, August 7-9, ,pp. 176-186, 1997.

[12] Prochaska, A., Santi, P., Higgins, J. \& Cannon, S., Debris-flow run-out predictions based on the average channel slope (ACS). Engineering Geology, 98, pp. 29-40, 2008. doi: http://dx.doi.org/10.1016/j.enggeo.2008.01.011

[13] Iverson, R., The debris-flow rheology myth. Debris-flow hazards mitigation: Mechanics, prediction, and assessment, Vol. 1, eds. D. Rickenmann, \& C. Chen, Millpress: Rotterdam, pp. 303-314, 2003.

[14] Corominas, J., The angle of reach as a mobility index for small and large landslide. Canadian Geotechnical Journal, 33, pp. 260-271, 1996. doi: http://dx.doi.org/10.1139/ $\underline{\mathrm{t} 96-005}$

[15] Toyos, G., OramasDorta, D., Oppenheimer, C., Pareschi. M., Sulpizio, R. \& Zanchetta, G. GIS-assisted modelling for debris flow hazard assessment based on the event of May 1998 in the area of Sarno, southern Italy: Part I: Maximum run-out. Earth Surface Processes and Landforms, 32, pp. 1491-1502, 2006. doi: http://dx.doi.org/10.1002/ $\underline{\text { esp. } 1472}$

[16] Mambretti, S. Valutazione della magnitudo di colate detritiche in funzione del tempo di ritorno nel Bacino di Val Gola (BG). GEAM, 1, pp. 15-24, 2007 (in Italian).

[17] De Wrachien, D. \& Mambretti, S., Assessment of debris flow magnitude in small catchments of the Lombardy Alps: the Val Gola case study. Agricultural Sciences, 2(1), pp. 9-15, 2011. doi: http://dx.doi.org/10.4236/as.2011.21002

[18] Iverson, R.M., The physics of debris flows. Reviews Geophysics, 35(3), 245-296, 1997. doi: http://dx.doi.org/10.1029/97RG00426

[19] Ghilardi, F., Ghilardi, S. \& Mambretti, S., Studio di dettaglio della conoide della Val Gola in comune di Costa Volpino. Technical Report, 2006 (in Italian).

[20] Takahashi, T., Debris Flow. International Association for Hydraulic Research: Balkema, Rotterderdam.

"This is a revised version of the paper published in WIT Transactions on Engineering Sciences, Vol 73, (C) 2012 WIT Press, www.witpress.com, ISSN 1743-3533 (on-line), doi: 10.2495/ DEB120011." 